Indexaciones: Repositorio de Revistas UCR, DIALNET, Latindex, REDALYC Directorio y recolector de recursos digitales del Ministerio de Cultura de España, Directory of Open Access Journals. Diálogos Revista Electrónica de Historia ISSN 1409-469X. Número especial 2008. Dirección web: http://historia.fcs.ucr.ac.cr/dialogos.htm

\section{Divide y vencerás}

\section{Luisa Angelina González César.}

Sur 22 Núm. 17 Colonia Agrícola Oriental C.P. 08500

México D.F.

Teléfono: 555580956

Correo electrónico: Luisaa.cesar@gmail.com

Estudiante del posgrado en Geografía.

De la Universidad Nacional Autónoma de México. 


\section{La desigualdad espacial}

En todos los tiempos la organización social ha sido estigmatizada por quienes se ven amenazados con perder o restar su poder y control sobre los medios de producción, o sobre el poder del Estado; en la historia se encuentran numerosos relatos de la trayectoria en la que transitaron las organizaciones civiles, integradas por obreros, campesinos, indígenas y estudiantes, principalmente, quienes han encontrado en la movilización el medio para el reconocimiento de derechos y necesidades apremiantes para su reproducción social; así mismo, su impacto es posible verlo ya sea a nivel local, regional y nacional.

La inconformidad social ha estado generalmente asociada con las condiciones de vida, de trabajo y con el despojo de los medios de producción, teniendo como consecuencia la producción de espacios desiguales; el punto de partida para entender el proceso que conlleva a un espacio a ser distinto a otro radica en el modo de producción capitalista, quien determina las relaciones sociales de producción y las formas en que se relacionan los elementos del espacio (la sociedad, la instituciones, la empresa y el medio ecológico, según Milton Santos, 1986¹).

Cada uno de los elementos que producen al espacio social se relacionan de manera diversa, la fuerza e influencia que tenga uno sobre los otros se encuentra determinada por el momento histórico, definido esté último por la forma que adopta el capitalismo; por lo tanto, la fuerza de trabajo, la empresa, las instituciones del Estado y el medio ecológico adquieren interpretaciones y relaciones distintas según la mascara que adopte el modo de producción capitalista, llámese producción fordista, flexible, global o neoliberal.

De manera general la trayectoria que han tenido los elementos del espacio al interior del modo de producción capitalista mantienen la división social, el poder concentrado, la acumulación

1 Santos, Milton. Espacio y método. (Barcelona: Geocrítica, 1986, Núm. 65). 
de capital y la naturaleza secundaria en constante transformación; la empresa, bajo su principio de generación de plusvalía, modifica los tiempos de trabajo, los salarios, las condiciones de trabajo, la producción, el consumo e interviene sobre las instituciones del Estado; por su parte, las instituciones que integran al Estado conservan su apego a las necesidades de la empresa, actuando en su favor a través de las políticas públicas, creando y reformando las leyes que regulan la conducta social, el medio ecológico, el Estado y la misma empresa, para satisfacer las necesidades de ella, sin perder su poder concentrado en las burocracias; por último, la fuerza de trabajo representada por el obrero, campesino e indígena mantiene la cualidad de ser quien vende su trabajo a cambio de un salario, el cual es íntegramente destinado para su reproducción social, por lo que éste debería ser suficiente para cubrir todas aquellas necesidades que el obrero requiere para mantener un nivel de vida satisfactorio al momento histórico.

\section{Los derechos ganados y derechos perdidos}

Según Santos (2003), a partir de que el paradigma de la modernidad, formulado durante la Ilustración, $<<$ converge y se reduce al desarrollo capitalista, las sociedades modernas pasaron a vivir [en] la contradicción entre los principios de emancipación $>><<y$ los principios de regulación>>. Los principios de emancipación apuntan a la igualdad y la integración social, mientras que los principios de regulación rigen los procesos de desigualdad y de exclusión, generados por el mismo desarrollo del capitalismo.

Para el mismo autor, la desigualdad y la exclusión $<<$ son dos sistemas de pertenencia jerarquizada $>>$; en el caso del sistema de desigualdad, $<<$ la pertenencia se da por la integración subordinada $>>$, que $<<$ implica un sistema jerárquico de integración social. Quien se encuentra abajo está dentro, y su presencia es indispensable $>>$; en el sistema de exclusión $<<$ la pertenencia se da por exclusión >>, presuponiendo <<un sistema igualmente jerárquico pero dominado por el 
principio de la exclusión: se pertenece por la forma como se es excluido. Quien está abajo, está afuera $>>^{2}$, es decir, no es necesario.

La producción del espacio social ha estado fuertemente influenciada por los principios de la emancipación y regulación, debido a que dado el momento histórico pueden ser la causa o consecuencia de la organización y movilización social; dos claros ejemplos del uso del principio de la emancipación que motivaron la organización y el levantamiento de una parte de la sociedad, son la Revolución Francesa de 1789 y la Revolución mexicana de 1910, en donde la libertad y la igualdad fueron causas buscadas a través de la lucha armada.

En el caso de la Revolución Francesa, el aporte heredado consistió precisamente en esos principios que representan la emancipación social: la libertad, igualdad y fraternidad. Francia posee una amplia trayectoria en la cuestión de los derechos humanos, la necesidad de proclamar una Constitución que rigiera las relaciones de la nación, estuvo acompañada por la Declaración de los derechos del hombre y del ciudadano (1789), en cada una de las declaraciones en principio de reconoce: libertad e igualdad de derechos entre los hombres, libertad, propiedad privada, un juicio justo, entre otros; a medida que fueron generándose las posteriores declaraciones se fueron agregando otros derechos, tales como el salario, educación, salud, libertad de expresión, de reunión y organización sindical $(1793,1848)$.

La mayoría de los anteriores derechos fueron retomados para suscribir la Declaración Universal de los Derechos Humanos, de 1948; la cual se generó a fin de evitar que se cometiesen en el futuro los mismos acontecimientos de la Segunda Guerra Mundial, en contra de cualquier ser humano o grupo social. Los derechos que forman parte de la declaración son interpretados como derechos naturales para toda persona al momento de su nacimiento, por lo que no puede negarse 2 Santos, Boaventura de Sousa. (2003). La caída del ángelus novus: Ensayo para una nueva teoría social y una nueva práctica política. (Bogotá, Colombia: Instituto Latinoamericano de Servicios Legales Alternativos - Universidad Nacional de Colombia, 2003), 125-126. 
a ningún ser humano su acceso y ejercicio; el primer artículo además de mostrar claramente la influencia francesa en materia de derechos humanos, reconoce a todos los seres humanos la libertad e igualdad en dignidad y derechos y, dotados como están de razón y conciencia, deben comportarse fraternalmente los unos con los otros.

Otros más de los derechos de amplia trayectoria son: el derecho a la vida y seguridad (artículo 3), la prohibición de aquellas prácticas de esclavitud, servidumbre y trata de personas (artículo 4), igualdad ante la ley y la protección de la misma (artículo 7), el derecho a circular libremente en el territorio de un Estado (artículo 13), la propiedad como un derecho individual y colectivo, así como la negativa de su privación de forma arbitraria (artículo 17), a la libertad de opinión y expresión (artículo 19), el derecho de toda persona a la libertad de reunión y de asociación pacífica (artículo 20), a participar en el gobierno de su país, directa o indirectamente (artículo 21), a la seguridad social y la satisfacción de los derechos económicos, sociales y culturales (artículo 22), el derecho al trabajo en condiciones equitativas y satisfactorias, a la protección contra el desempleo, a igual salario por igual trabajo, la remuneración debe ser equitativa y satisfactoria para asegurar la existencia conforme a la dignidad humana, a fundar sindicatos y a sindicarse para la defensa de sus intereses (artículo 23), el derecho a un nivel adecuado de vida que le asegure tanto a la persona como a la familia la salud y el bienestar, la alimentación, el vestido, la vivienda, la asistencia médica y los servicios sociales necesarios (artículo 24), y el derecho a la educación (artículo 26). ${ }^{3}$

Recuperando nuevamente los motivos que llevaron a los obreros, campesinos, indígenas y estudiantes a la movilización, se resumen en la búsqueda de la libertad, igualdad, salario justo, mejoramiento en las condiciones de trabajo, acceso a la educación y salud; una vez que se obtuvo

3 Corcuera Cabezut, Santiago. Derecho constitucional y derecho internacional de los derechos humanos. (México: Oxford, 2002). 
su reconocimiento a nivel internacional, cada uno de ellos debía tener su reflejo al interior de las leyes que regula la conducta de las naciones, en algunos casos como en México, la Constitución de 1917, ya alberga en su interior la gran mayoría de los derechos que protegen al ciudadano, incluyendo a toda persona extranjera que se encuentre al interior del territorio. Sin embargo, además de los derechos que están dirigidos al individuo en la Constitución mexicana, existe un derecho puramente social, el artículo 27 (antes de su reforma) contenía entre sus puntos el derecho de acceso a la tierra para aquellas personas que dependían de su explotación para su reproducción social, al Gobierno Federal se le otorga y obliga, el poder y acción respectivamente para expropiar los latifundios (propiedad privada) y distribuir la tierra entre aquellos que carecían de la misma, además de determinar la extensión máxima que deberían tener todas las propiedades privadas y colectivas, según su uso. Además para evitar que en el futuro se volviera a concentrar la tierra en pocas manos, sólo el Gobierno Federal podía hacer las concesiones a los particulares, sociedades civiles o comerciales, bajo el requisito de ser mexicano por nacimiento o naturalización; restringiendo su posesión, explotación e intercambio de la tierra según sea el caso a los extranjeros, asociaciones religiosas, instituciones de beneficencia, sociedades comerciales y Bancos.

A través del reparto agrario los campesinos y grupos indígenas del país accedieron a la tierra agrícola, una vez que fueron dotados de tierras debían conformar y regirse a través de la figura del ejido o explotación comunal; las cuales se encontraban protegidas conforme a la ley agraria, con el fin de evitar la enajenación, embargo o renta de la misma.

El derecho de acceso a la tierra contenido en la Constitución mexicana, se contraponía con el derecho a la propiedad privada de la Declaración Universal de Derechos del Hombre, la protección de la propiedad privada ha estado presente desde la Declaración del buen pueblo 
de Virginia en 1776, pasando posteriormente a las diversas declaraciones de derechos del hombre de Francia, y recuperada en la declaración universal; el derecho a la propiedad puede ser cuestionado al presentarse como un derecho de carácter natural para todo ser humano, él mismo no ha sido causa de lucha por parte de los obreros, campesinos, indígenas y estudiantes. Pero lo que si es, es un derecho de clase, ya que debe su permanencia a que en todo momento las leyes han sido pensadas y suscritas por la clase burguesa, en o con alianza del poder del Estado, es un derecho que reproduce las relaciones sociales de producción de tipo capitalista, y por lo tanto la estructura de clases, la división del trabajo y la desigualdad espacial. Por lo tanto, el acceso a la tierra se enfrenta a la lógica de la reproducción del capital, por lo que su reforma y suspensión, fue punto prioritario dentro de la ola de reformas estructurales que vivieron las naciones a partir de la década de los años setenta del siglo pasado.

El artículo 17 de la Constitución mexicana, tuvo su mayor reforma en enero de 1992, el ex presidente Carlos Salinas dio por finalizado el reparto agrario en toda la nación, otorgando títulos de propiedad de las extensiones que poseían los ejidatarios y comuneros, para su explotación, convirtiéndose oficialmente en pequeños propietarios e insertando a la tierra al libre mercado. La reforma y derogación del derecho al acceso a la tierra representa un retroceso real de beneficio colectivo, masivo y generador real de igualdad social.

Tanto los derechos individuales como los sociales son uno de los medios para que aquellos espacios producidos bajo condiciones de desigualdad puedan ser integrados a la dinámica social, sin embargo la tendencia a desvanecer y reducir a los derechos sociales, para únicamente preservar a los individuales perpetua la desigualdad social y genera un dinámica de relaciones que dirigen a sectores de la población a un estado de exclusión. 


\section{La Yerbabuena, un ejido en peligro de extinción}

En el territorio mexicano, pese a que la dotación de tierras fue concluida junto con la distinción oficial del ejido (como una forma alterna de tenencia de la tierra, junto con el de la propiedad comunal), existen aún grupos de campesinos que mantienen activa la figura del ejido, para establecer las relaciones al interior de la comunidad, conservando y rigiéndose bajo las figuras del comisario ejidal, tesorero, secretario y vocal, además de llevar a cabo las asambleas reglamentarias y tomar en ellas las decisiones que involucran al grupo; este es el caso del ejido de La Yerbabuena, en el estado de Colima.

La Yerbabuena es uno más de los ejidos que deben su origen a partir de que en la Constitución mexicana se reconoce el derecho y acceso a la tierra, los ejidatarios de la Yerbabuena, antes de haber recibido las tierras para su explotación, fueron parte de la fuerza de trabajo conocida como peones acasillados, quienes laboraban al interior de las haciendas. Los primeros ejidatarios de la Yerbabuena eran parte de esa fuerza de trabajo de la ex hacienda San Antonio, la cual llegó a cubrir una extensión de 3, 392.20 hectáreas; una vez que entró en vigor la Constitución (1917) y que dio inicio el reparto agrario, los trabajadores de la ex hacienda realizaron su primera solicitud (1934), en donde se alude a la falta de tierras y su necesidad para vender su fuerza de trabajo, para pedir una dotación de tierras a fin de mejorar su calidad de vida. ${ }^{4}$

No obstante la existencia del derecho y la viabilidad para ejercerlo, pudo más las prácticas de división, para que los trabajadores de la ex hacienda desistieran de continuar con el trámite respectivo, los dueños de la misma les ofrecieron a los trabajadores la posibilidad de crear un sindicato y la contratación colectiva, dentro del contrato se especificó la prestación de poder trabajar las tierras de la hacienda, gozando de los frutos que del trabajo se generen; bajo tal 4 "Periódico Oficial del Gobierno Constitucional del estado de Colima". Sábado 22 de septiembre de 1934. 
argumento los solicitantes se negaron a continuar con el trámite respectivo, y pasaron a formar parte del Sindicato Rojo de Agricultores en Pequeño.

Posteriormente, quienes quedaron excluidos de pertenecer al sindicatos y de gozar de aquellos beneficios especificados en el contrato colectivo, volvieron a solicitar tierras a las autoridades correspondientes (1941), empero para cuando las autoridades agrarias se trasladaron al poblado ubicado al interior de la ex hacienda, quienes habían realizado la solicitud habían desaparecido y sólo algunas personas accedieron a que se les dotara de tierras, pero no afectado la hacienda sino en un ejido cercano, en donde existían aún lugares y que ellos mismo ocuparon.

La segunda etapa de solicitudes, da inicio cuando nuevamente los trabajadores de la ex hacienda envían un tercera petición (1955), al gobernador del estado de Colima, quien en respuesta realiza los trabajos correspondientes para llevar a cabo la dotación, no obstante de reconocer a 153 personas con la capacidad de ser dotados por cumplir con todos los requisitos que marcaba la ley agraria, se argumenta la inexistencia de tierras con posibilidad para ser expropiadas, debido a que lo que se tienen en un radio de 7 kilómetros son pequeñas propiedades con certificado de inafectabilidad en trámite, por lo que se dejan a salvo los derechos de los 153 capacitados, para que se hagan valer en tiempo y forma a sus intereses. ${ }^{5}$

Por último, no conformes con la respuesta del Gobierno del Estado, el grupo de solicitantes envía la petición al Gobierno Federal, en 1958, quien en 1967 resuelve dotar de tierras a 31 capacitados, las cuales fueron tomadas de la ex hacienda conocida como la Joya y su rancho anexo la Yerbabuena, ya que la propiedad contaba con la superficie necesaria para beneficiar a un grupo de 26 personas, la superficie a expropiar fue de 1531.12 hectáreas, las cuales estaban catalogadas como: 553.52 hectáreas de temporal, 641 hectáreas de agostadero y 336 hectáreas

5 "Diario Oficial de la Federación". Viernes 17 de enero de 1958. 
de terreno cerril. ${ }^{6}$

Sin embargo, la superficie que actualmente conserva el ejido corresponde a una superficie de 464 hectáreas, debido a que los dueños de la ex hacienda de la Joya y su rancho anexo la Yerbabuena, previendo la oleada de expropiación de los latifundios y de conocer la resolución presidencial, optaron por fragmentar la propiedad y vender parte de la misma, antes de que los capacitados fueran formalmente informados y dotados, es por ello los nuevos dueños interpusieron juicios de amparo en contra de la resolución presidencial, bajo el argumento de ser pequeña propiedad. Por lo que el ejido tuvo que devolver primero 515 hectáreas y posteriormente 542 hectáreas más.

Una vez que el grupo se avocó a trabajar las tierras que le restaron, tuvieron distintas etapas de trabajo, en donde en un tiempo se trabajo de forma colectiva y posteriormente de manera individual. El ejido dedica parte de la tierra a la producción del café, el cual representa su fuente de ingreso, mientras que una pequeña parte se cultiva el maíz, exclusivamente para su consumo.

Durante 34 años, tanto las familias de los ejidatarios como las de los vecinos, vivieron en el poblado de la Yerbabuena, a partir del 2002 la población fue reubicada a un nuevo lugar, esto obedeció a que el ejido está localizado a 8 kilómetro del volcán de Colima, considerado un volcán activo y peligroso según los registros geológicos; los yerbabuenenses ya habían experimentado las constantes erupciones del volcán, manteniendo con él una relación de tipo "natural", no era considerado peligros, riesgoso o amenazante a sus vidas; empero una vez que las manifestaciones del volcán fueron más recurrentes e intensas; un grupo de científicos de la Universidad de Colima, envió un grupo a la comunidad para informar y alertar de los "peligros"

6 “Diario Oficial de la Federación”. Miércoles 5 de julio de 1967. 
a los que estaban expuestos, mediante videos de otros volcanes haciendo erupción, fotografías y diagramas el grupo informó a la población sobre el riesgo que corrían al vivir cerca del volcán, se preparó a la gente para salir de sus viviendas y ser trasladados a albergues cada vez que el volcán presentaba una erupción y que los científicos consideraban era peligrosa.

La intervención del Ejército mexicano, fue requerida debido a que la comunidad no contaba con transportes propios o públicos para su desalojo, además de que para su acceso se debía cruzar un río que provenía del volcán, el cual durante la temporada de lluvias crecía considerablemente, trayendo consigo material rocoso de gran tamaño, lo que comúnmente obstaculizaba el paso dejando a la gente de la Becerrera y de la Yerbabuena incomunicada; si bien el ejército sólo era el encargado de coordinar y llevar a cabo las evacuaciones, éste aún permanece en el poblado.

Al mismo tiempo en que se realizaron las evacuaciones, se llevaron a cabo obras de infraestructura, el gobierno del estado construyó el puente sobre el río, en la zona urbana del ejido se dotó de alumbrado público, se realizaron obras de banquetas y el empedrado en las calles. En tanto, al mismo tiempo Protección Civil del estado, representantes del gobierno estatal y el grupo de científicos de la Universidad de Colima, propusieron reubicar a la población; para ello se hizo una labor de convencimiento sobre el peligro y la seria amenaza que representaba el hecho de vivir cerca con un volcán activo, discurso que fue aceptado y asumido como cierto por la población; sumado al discurso, la población ya se encontraba poco dispuesta de estar constantemente saliendo de sus viviendas para pasar hasta 30 días viviendo en un albergue, con la preocupación de perder sus pertenencias por robo, de que sus animales se murieran de hambre, de saber que alguno de los miembros de la familia se rehusaban a salir o que se quedaban para cuidar las pertenencias, etcétera. Cabe decir, que tanto ejidatarios como vecinos de la 
Yerbabuena, complementa su gasto familiar laborando en la empresa llamada el Jabalí y el hotel San Antonio, ambas antes fueron parte de la ex hacienda San Antonio; las cuales se encuentran también cerca del volcán, durante el tiempo en que la población fue desalojada y llevada a los albergues, aquellos que trabajaban en el Jabalí y en el hotel, continuaban su labor, de la empresa se enviaron camionetas para trasladar a los trabajadores.

Después de que se tuvo el proyecto de las viviendas y del lugar en donde se construirían, la población fue informada para conocer su respuesta, siendo está afirmativa debido a que ya no estaban dispuestos a permanecer más tiempo en los albergues, por lo que aceptaron su traslado a la zona urbana de Cofradía de Suchitlán, en donde se construyeron las casas en un extremo del poblado.

La colonia la Yerbabuena es ahora parte de la comunidad de Cofradía de Suchitlán, empero no todos los pobladores del antiguo poblado se ha trasladado a nuevo, han surgido numerosos problemas: división social, fractura de relaciones, venta de tierras ejidales, migración e intervención de grupos externos sobre algunas familias de la Yerbabuena.

El grupo antes de su reubicación generó relaciones sociales entre su población, dio cohesión y capacidad de organización entre las mujeres, los niños y jóvenes por ser un número reducido mantuvieron una relación estrecha unos con otros, y los hombres se integraron a través de la organización resultante del ejido; una vez que la población fue reubicada, algunas familias se opusieron y optaron por permanecer en el antiguo poblado, las cuales fueron fuertemente influenciadas por grupos simpatizantes al zapatismo, quienes les han inculcado prácticas y rituales "prehispánicas"; dos familiares han encontrado en el ritual del temascal, el medio para vivir; mientras que otras familias dependen de las ayudas públicas para su reproducción, en otro 
caso la venta de la tierras le ha permitido mantenerse, por último aquellos que no poseían tierras y que aún permanecen habitando en el antiguo poblado laboran en los Ranchos cercanos.

Mientras tanto las familias que actualmente habitan en la colonia la Yerbabuena, en Cofradía, han dedicado más tiempo a la búsqueda de trabajo por el incremento de los gastos familiares, consistentes en la compra de la mayor parte de los productos para la alimentación, el incrementó en el consumo de la luz; la satisfacción de nuevas necesidades creadas a partir de su integración a un centro urbano de mayor tamaño, como la posesión de telefonía fija y móvil, transporte privado, combustible (leña y gas) para la realización de los alimentos, etcétera. Las relaciones y organización de las mujeres se han perdido, debido a la inserción de algunas al campo laboral; los jóvenes lejos de continuar sus estudios se insertan a la actividad productiva, algunos conservan ir a trabajar al Jabalí y el hotel San Antonio, y en otros casos recurren trabajar en la misma comunidad de Cofradía, o trasladarse a Suchitlán, Cómala, la ciudad de Colima y muy recientemente a Estados Unidos de Norte América; los niños han dejado de convivir exclusivamente con los de la colonia, ahora interactúan con la población infantil de Cofradía, además de incrementar el consumo de productos llamados chatarra, elevando en algunos casos el peso y pérdida de dientes por caries; por último, los hombres que poseían las tierras del ejido muestran una tendencia a vender sus propiedades, desde los predios en donde se ubicaban sus viviendas hasta las parcelas; la venta es justificada por la falta de transporte para trasladarse cotidianamente, la imposibilidad física, la inversión de tiempo y dinero para continuar con la producción del café misma que no es considerada redituable; y en el menor de los casos combinan la explotación de la tierra con un trabajo que llevan a cabo en alguna propiedad privada durante los 5 días de la semana, dejando los fines de semana para su propiedad.

Recientemente, algunos de los ejidatarios fueron informados sobre la posibilidad de crear 
un centro eco-turístico en el antiguo poblado de la Yerbabuena, para lo cual tienen la posibilidad de recibir apoyos económicos, a través de la asamblea ejidal el grupo ha planteado la posibilidad, no obstante la venta de las tierras por parte de algunos ejidatarios, estos conservan su permanencia por que el ejido mantiene una extensión destinada a la explotación comunal, por lo que el voto de los 26 ejidatarios es requerido. La opción de crear un centro turístico contradice la condición de peligro y alto riego que fue determinada, por los científicos y autoridades del estado, a la región; por otro lado, la venta de los solares también alimenta la serie de contradicciones, ya que sí lo que se buscó fue salvar la vida de los yerbabuenenses ahora se tiene un repoblamiento del lugar por personas venidas de Colima y otros lugares, según lo expresaron algunas de las personas que han vendido sus propiedades.

La población yerbabuenense, se ha insertado a una dinámica distinta de producción de su propio espacio, las relaciones sociales que están estableciendo se encuentran determinadas por un capitalismo generador de desigualdad, su traslado obligó a los miembros de la familia a insertarse a la vida laboral y de consumo, el deseo y las necesidades se mezclan para ser un centro de consumo de alimentos, productos para el hogar, productos personales, actividades recreativas, etcétera, quienes tienen para solventarlas son mal vistos por aquellos que no pueden; no existen los lugares de reunión en el nuevo lugar, contrario a lo que sí se tenía en el antiguo. Existe un presente que se está produciendo con los principios de la emancipación y con los de la exclusión.

\section{Conclusiones}

El grupo que aún permanece en el antiguo poblado se encuentra en permanente vigilancia, por parte del Ejército mexicano, mientras que la otra parte de la población actúa a través de la relación familiar nuclear, dejando atrás las relaciones de comunidad. 
Divide y vencerás es la práctica más efectiva que se ha utilizado para que los grupos accedan y ejerzan su derecho, desvanecer los derechos sociales es parte de la dinámica de división, lo individual resurge para ser competitivos en la búsqueda y conservación del trabajo, para el consumo y la satisfacción de necesidades.

Los grupos que insisten en la organización son acusados de querer obtener mayores beneficios a costa de los demás, por lo que día a día se reducen las vías la renovación del grupo; dividir a la población de la Yerbabuena, ha sido la vía para el despojo de los bienes, la inevitable desaparición de la aún insipiente organización de ejidatarios individualiza los problemas y reduce la posibilidad de su solución. La desigualdad entre la población y la exclusión produce un espacio desigual con la venia del poder de las leyes, el poder del Estado y principalmente con la del capital. 